\title{
$3 \mathrm{AKOH}$ \\ И ПРАВОПОРЯДОК
}

\author{
В. М. Быков
}

\section{ПРАВОВОЕ ПОЛОЖЕНИЕ СЛЕДОВАТЕЛЯ В УГОЛОВНОМ ПРОЦЕССЕ РОССИИ (ЧАСТЬ З)}

\begin{abstract}
Аннотация. В статье рассматриваются правовые отношения следователя с прокурором, которые складываются в настоящее время между ними на основании нового Федерального закона РФ от 28 декабря 2011 года №404-Ф3. Автор в связи с этим подвергает критики ряд положений нового закона и указывает, что правовые отношения следователя и прокурора более удачно были регламентированы в cm. 127 УПК РСФСР, в связи с чем, предлагает в этой части использовать опыт уголовно-процессуального законодательства РСФСР.
\end{abstract}

Ключевые слова: юриспрудениия, новый закон, следователь, прокурор, уголовное дело, возбуждение дела, указание прокурора, самостоятельность следователя, руководитель следственного органа, усовершенствование закона.

\section{5. Правовые отношения следователя с прокурором}

овый Федеральный закон РФ от 28 декабря 2010 года №404-Ф3 «О внесении изменений в отдельные законодательные акты Российской Федерации в связи с совершенствованием деятельности органов предварительного следствия» ввел п. 5-1 в ч. 2 ст. 37 УПК РФ, которая непосредственно касается правовых отношения следователя с прокурором. ${ }^{1}$

В соответствии с этой новой нормой прокурор теперь получил право: истребовать и проверять законность и обоснованность решений следователя или руководителя следственного органа об отказе в возбуждении, приостановлении или прекращении уголовного дела и принимать по ним решения в соответствии с УПК РФ.

В связи с принятием этого нового Федерального закона РФ от 28 декабря 2010 года №404-Ф3 в науке уголовного процесса сразу же возникла оживленная дискуссия, которая непосредственно касается как прав прокурора на предварительном следствии, так и его правовых отношений со следователем.

Как известно, в настоящее время прокурор является должностным лицом, уполномоченным в пределах компетенции, предусмотренной УПК РФ, осуществлять от имени государства уголовное преследование в ходе уголовного судопроизводства, а также надзор за процессуальной деятельностью органов дознания и предварительного следствия (ч. 1 ст. 37 УПК РФ).

' Собрание законодательства Российской Федерации. 2011. №1. Ст. 16 .
Правовые отношения следователя с прокурором возникают уже на стадии возбуждения уголовного дела. Так как в соответствии с ч. 1 ст. 144 УПК РФ следователь обязан принять, проверить сообщение о любом совершенном или готовящемся преступлении и принять по нему решение.

Следует заметить, что новый Федеральный закон РФ от 9 марта 2010 года №19-Ф3 «О внесении изменений в Уголовно-процессуальный кодекс Российской Федерации» несколько расширил права следователя при проверке сообщения о преступлении, предусмотренные ныне новой редакцией ч. 1 ст. 144 УПК РФ. ${ }^{2}$

Прежняя редакция ч. 1 ст. 144 УПК РФ серьезно ограничивала права следователя при проверке сообщения о преступлении, сводя все его права только к праву требовать производства документальных проверок, ревизий и привлекать к их участию специалистов. В литературе по этому вопросу справедливо указывалось, что тех процессуальных средств для проверки сообщения о преступлении, которые были указаны в прежнем законе, явно недостаточно для того, чтобы следователь мог принять обоснованное решение. ${ }^{3}$

Интересы же следователя в стадии возбуждения уголовного дела требовали расширения способов проверки сообщения о преступлении, так как от успешного собирания следователем доказательств в этой стадии во многом зависит, насколько принятое им решение будет законным и обоснованным - или о возбуждении, или об отказе в возбуждении уголовного дела. Теперь закон разрешает

\footnotetext{
2 Российская газета. 2010. 12 марта.
}

${ }^{3}$ Будченко В. Проверка поводов для возбуждения уголовного дела. //Законность. 2008. №11. С. 52-53. 
следователю дополнительно производить исследование документов, предметов, трупов и привлекать к участию в этих проверках, ревизиях, исследованиях специалистов, а также давать органу дознания обязательное для исполнения письменное поручение о проведении оперативно-розыскных мероприятий. ${ }^{4}$

В соответствии с п. 1 ч. 2 ст. 37 УПК РФ прокурор уполномочен проверять исполнение требований федерального закона при приеме, регистрации и разрешении сообщений о всех преступлениях. Это положение уголовно-процессуального закона о правах прокурора в стадии возбуждения уголовного дела полностью распространяется на следователя, который по результатам проверки сообщения о преступлении принимает решения или об отказе в возбуждении уголовного дела, или о возбуждении уголовного дела.

Как установлено в п. 3 ч. 2 ст. 37 УПК РФ, прокурор имеет также право требовать от следственных органов устранения нарушений федерального законодательства, допущенные в ходе предварительного следствия.

Однако, прокурор по рассматриваемому нами новому Федеральному закону РФ от 28 декабря 2010 года №404Ф3 снова не получил права самостоятельно возбуждать уголовное дело. Теперь при необходимости возбуждения уголовного дела по своей инициативе в соответствии с п. 2 ч. 2 ст. 37 УПК РФ прокурор имеет право только вынести мотивированное постановление о направлении соответствующих материалов в следственный орган для решения вопроса об уголовном преследовании по фактам выявленных прокурором нарушений уголовного законодательства.

При этом получение следователем постановления прокурора с соответствующими материалами еще не предрешает положительное решение вопроса о возбуждении уголовного дела по этим материалам: в любом случае следователь должен решать вопрос о возбуждении уголовного дела самостоятельно и с учетом наличия для этого достаточных оснований.

Рассматриваемый Федеральный закон от 28 декабря 2010 года №404-Ф3 ввел в ст. 148 УПК РФ новую ч. 1.1, в которой указывается, что решение следователем об отказе в возбуждении уголовного дела в связи с мотивированным постановлением прокурора о направлении соответствующих материалов в орган предварительного следствия для решения вопроса об уголовном преследовании по фактам выявленных прокурором нарушений уголовного законодательства, вынесенное на основании п. 2 ч. 2 ст. 37 УПК РФ, может быть принято только с согласия руководителя следственного органа.

\footnotetext{
${ }^{4}$ Подробнее об этом см.: Быков В. М. Новый закон о проверке следователем сообщения о преступлении. //Право и политика. 2011. №7. С. 1115-1121.
}

Это последнее положение нового закона весьма существенно, на наш взгляд, ограничивает процессуальную самостоятельность следователя в решении вопроса об отказе в возбуждении уголовного дела. Вот возбудить уголовное дело в этом случае следователь может, а отказать в его возбуждении закон следователю не доверяет.

Казалось бы, что возбуждение уголовного дела - это более ответственное решение следователя, так как оно в дальнейшем влечет за собой самые серьезные правовые последствия: задержание подозреваемого, избрание меры пресечения в отношении подозреваемого и обвиняемого, привлечение лица в качестве обвиняемого и т.д. Удивительно, что принять такие решения следователю по закону теперь дозволяется, а отказывать в возбуждении уголовного дела - нет! По меньшей мере, это весьма странная позиция законодателя.

Новый Федеральный закон РФ от 28 декабря 2010 года №404-Ф3 также ввел новый п. 5-1 в ч. 2 ст. 37 УПК РФ. В соответствии с этой новой нормой прокурор получил теперь право: истребовать и проверять законность и обоснованность решений следователя или руководителя следственного органа об отказе в возбуждении, приостановлении или прекращении уголовного дела и принимать по ним решения в соответствии с УПК РФ.

Как правильно пишет А. П. Кругликов: «Возвращение прокурору полномочий по отмене указанных необоснованных и незаконных постановлений следователя и руководителя следственного органа, несомненно, усиливают его роль в осуществлении уголовного преследования и руководстве им». ${ }^{5}$

Однако, и теперь по новому закону постановление прокурора о направлении соответствующих материалов в орган предварительного расследования для решения вопроса об уголовном преследовании в соответствии с п. 4 ч. 1 ст. 140 УПК РФ рассматривается законодателем, как только повод для возбуждения уголовного дела.

В.Н. Григорьев увидел положительное значение нового закона в том, что «выделение постановления прокурора из числа иных источников сведений о преступлении в самостоятельный повод для возбуждения уголовного дела подняло его статус, привлекло внимание, что немаловажно для правоприменительной практики, особенно в начальный период действия законодательных новел». ${ }^{6}$

Это утверждение автора, на наш взгляд, представляется весьма спорным. Как можно увидеть какое-то положительное значение нового закона, когда по нему правовое

\footnotetext{
${ }^{5}$ Кругликов А. П. Проблемы процессуальных отношений прокурора со следователем и руководителем следственного органа. //Российская юстиция. 2011. №10. С. 29.

${ }^{6}$ Григорьев В. Постановление прокурора - новый повод для возбуждения уголовного дела? //Законность. 2011. №8. С. 47.
} 
положение прокурора законодателем сведено до положения обычного заявителя, просителя?

Следует напомнить положения ч. 1 ст. 37 УПК РФ, в соответствии с которой прокурор является должностным лицом, уполномоченным в пределах компетенции, предусмотренной УПК РФ, осуществлять от имени государства уголовное преследование в ходе уголовного судопроизводства, а также надзор за процессуальной деятельностью органов дознания и предварительного следствия. И вот теперь и по новому закону прокурор, вместо того, чтобы иметь право лично возбудить уголовное дело и направить его следователя для расследования, вынужден просить следователя о возбуждении уголовного дела! Более неразумное положение нового закона просто трудно придумать!

Получается, что прокурор обращается со своим постановлением о возбуждении уголовного дела и решении вопроса об уголовном преследовании к следователю, за деятельностью которого он сам должен осуществлять надзор. Законодателю, на наш взгляд, следовало предоставить право прокурору самому принимать решения о возбуждении уголовного дела, а не возводить в УПК РФ малообоснованные новые процессуальные конструкции в виде нового повода возбуждения уголовного дела.

В науке уголовного процесса в настоящее время запрет права прокурора на возбуждение уголовного дела активно обсуждается. Так, ряд авторов считают, что прокурор должен иметь право возбуждать уголовное дело. Такое мнение, например, высказывает Д. Ережепалиев. ${ }^{7}$

А. Соловьев и М. Токарева, анализируя положения нового закона, пишут: «Оптимально было бы восстановить имевшиеся у прокурора ранее права по личному усмотрению выявленных им нарушений закона путем возбуждения им уголовного дела и отмене незаконного решения следователя об отказе в возбуждении уголовного дела». 8

На наш взгляд, с такой позицией ученых законодателю следует согласиться и внести в УПК РФ необходимые изменения.

В отличие от права прокурора следователь в соответствии с ч. 1 ст. 146 УПК РФ имеет право самостоятельно в пределах своей компетенции возбудить уголовное дело, о чем он выносит соответствующее постановление. При этом ч. 4 ст. 146 УПК РФ в новой редакции требует, чтобы следователь копию постановления о возбуждении уголовного дела незамедлительно направил прокурору.

\footnotetext{
${ }^{7}$ Ережепалиев Д. Полномочия прокурора в стадии возбуждения уголовного дела. //Уголовное право. 2011. №4. С. 84.

${ }^{8}$ Соловьев А., Токарева М. Необходимо восстановить властнораспорядительные полномочия прокурора в досудебных стадиях российского уголовного судопроизводства. //Уголовное право. 2011. №4. С. 102.
}

Правда, новый закон делает одно исключение: если уголовное дело возбуждено капитанами морских или речных судов, находящихся в дальнем плавании, руководителями геолого-разведывательных партий или зимовок, удаленных от мест расположения органов дознания, главами дипломатических представительств или консульских учреждений РФ прокурор незамедлительно уведомляется указанными лицами о начатом расследовании.

В данном случае постановление о возбуждении уголовного дела передается прокурору незамедлительно при появлении для этого реальной возможности. В случае, если прокурор признает постановление о возбуждении уголовного дела незаконным и необоснованным, он вправе в срок не позднее 24 часов с момента получения материалов отменить постановление о возбуждении уголовного дела, о чем выносит мотивированное постановление (ч. 4 ст. 146 УПК РФ в новой редакции).

В остальных случаях в соответствии с ч. 6 ст. 148 УПК РФ в новой редакции прокурор, признав отказ следователя в возбуждении уголовного дела незаконным и необоснованным, выносит мотивированное постановление о направлении соответствующих материалов руководителю следственного органа для решения вопроса об отмене постановления следователя об отказе в возбуждении уголовного дела.

Это просто удивительно, что сам прокурор не может отменить незаконное постановление следователя, восстановить законность, а вынужден обращаться для решения этого вопроса к руководителю следственного органа. Что же касается таких постановлений дознавателя, то прокурор вправе отменить их сам, без обращения к начальнику органа дознания.

В таком же порядке решается вопрос об отмене незаконных и необоснованных постановлений следователя о прекращении уголовного дела или уголовного преследования. Признав постановление следователя незаконным и необоснованным, прокурор выносит мотивированное постановление о направлении соответствующих материалов руководителю следственного органа для решения вопроса об отмене постановления о прекращении уголовного дела, который отменяет постановление следователя и возобновляет производство по уголовному делу (ч. 1 ст. 214 УПК РФ в новой редакции).

А как быть, если руководитель следственного органа не согласен с позицией прокурора? То в этих случаях в соответствии с ч. 4 ст. 39 УПК РФ он просто «информирует прокурора о несогласии с его требованиями».

Дальнейший порядок действий прокурора в этих случаях установлен в ч. 6 ст. 37 УПК РФ в новой редакции. В случае несогласия руководителя следственного органа либо следователя с требованиями прокурора об устранении нарушений федерального законодательства, допущенных в 
ходе предварительного следствия, прокурор вправе обратиться с требованием об устранении указанных нарушений к руководителю вышестоящего следственного органа.

А если и руководитель вышестоящего следственного органа не согласен с указанными требованиями, то прокурор вправе обратиться к Председателю Следственного комитета при прокуратуре Российской Федерации или руководителю следственного органа федерального органа исполнительной власти. Если прокурор не найдет поддержки в указанных органах в решении вопросов об устранении нарушений федерального законодательства, допущенных в ходе предварительного следствия, то в дальнейшем новый закон разрешает прокурору обратиться к Генеральному прокурору РФ, решение которого является окончательным.

Как правильно заметил А. П. Кругликов, «из приведенных положений закона вытекает, что в названных случаях законность и обоснованность требований прокурора об устранении нарушений федерального законодательства проверяют в первую очередь, причем неоднократно, соответствующие руководители следственных органов (и даже следователь!)». ${ }^{9}$

Таким образом, выявляя и устраняя нарушения законности на предварительном следствии, в настоящее время прокурор практически лишен реальных и действенных мер прокурорского реагирования. Он не имеет права сам отменять незаконные и необоснованные постановления следователя, при серьезных нарушениях федерального закона не может возбудить уголовное дело, отстранить следователя, допустившего нарушения закона от ведения уголовного дела и т.д. - все эти вопросы он должен решать, обращаясь к руководителю следственного органа.

Вследствие этого, прокурор на предварительном следствии превратился в такую процессуальную фигуру, которая в значительной степени утратила свое процессуальное влияние на ход и результаты проводимого предварительного следствия по уголовному делу. По существу, прокурор должен выступать во всех указанных случаях в виде жалобщика, просителя, хотя по смыслу его надзорных функций должен бы иметь право отменять все незаконные и необоснованные решения следователя и его начальника своим постановлением. На наш взгляд, этот новый закон может в значительной степени подорвать режим законности на предварительном следствии.

В связи с этим представляются совершенно необоснованными предложения некоторых авторов, которые предлагают, по существу, деятельность самого прокурора полностью поставить под контроль суда. Так, например, В. А. Горленко полагает, что «статью 125 УПК дополнить частью 2-1 словами: «Дознаватель с согласия органа дозна-

${ }^{9}$ Кругликов А. П. Указ. выше раб. С. 30. ния, а следователь с согласия руководителя следственного органа вправе принести жалобу на решения прокурора в судебном порядке». ${ }^{10}$

Юридическую точность формулирования автором этого предложения мы оставляем на его совести. Но должны сразу заявить о полной неприемлемости данного предложения. Трудно себе представить эффективное предварительное следствие, когда участники стороны обвинения то и дело будут выяснять свои служебные отношения и свои позиции по уголовному делу в суде. Более бессмысленную ситуацию на предварительном следствии нам трудно себе даже представить.

Новый закон ввел еще одно весьма спорное положение, которое напрямую касается особенностей правовых отношений следователя с прокурором. Законодатель в ст. 37 УПК РФ ввел новую часть 2.1, в которой указывается, что по мотивированному письменному запросу прокурора ему предоставляется возможность ознакомиться с материалами находящегося у следователя в производстве уголовного дела.

В связи с этим А. П. Кругликов справедливо замечает: «Отсюда логичен следующий вывод: следователь может признать письменный запрос прокурора немотивированным и отказать ему в предоставлении материалов дела». ${ }^{11}$

Установленный новым законом порядок нам представляется не очень эффективным, так как полностью исключает возможность проводить прокурору внезапные проверки уголовных дел, находящихся в производстве у следователя, что явно не соответствует задачам надзорной деятельности прокурора.

Из других прав прокурора, связанных с деятельностью следователя. следует указать право прокурора изымать любое уголовное дело у органа дознания или материалы проверки и передавать его следователю с обязательным указаний оснований такой передачи (п. 11 ч. 2 ст. 37 УПК РФ).

Прокурор также имеет право передавать уголовное дело или материалы проверки сообщения о преступлении от одного органа предварительного расследования другому в соответствии с правилами, установленными ст. 151 УПК РФ. Кроме того, прокурор имеет право изымать любое уголовное дело или любые материалы проверки сообщения о преступлении у органа предварительного расследования федерального органа исполнительной власти и передавать их следователю Следственного комитета РФ с обязательным указанием оснований такой передачи (п. 12 ч. 2 ст. 37 УПК РФ).

\footnotetext{
${ }^{10}$ Горленко В. А. Проблема установления баланса полномочий следователя и прокурора в решении вопроса о возбуждении уголовного дела. //Следователь. 2011. №3. С. 16.

${ }^{11}$ Кругликов А.П. Указ. выше раб. С. 30.
} 
Большое влияние на формирование правовых отношений следователя с прокурором оказывает его право утверждать обвинительное заключение по уголовному делу, поступившего прокурору от следователя с обвинительным заключением.

В соответствии с ч. 1 ст. 221 УПК РФ прокурор рассматривает поступившее от следователя уголовное дело с обвинительным заключением в течение 10 суток. В соответствии с новым законом в случае сложности или большого объема уголовного дела срок, установленный ч. 1 ст. 221 УПК РФ, может быть продлен по мотивированному ходатайству прокурора вышестоящим прокурором до 30 суток (ч. 1.1 ст. 221 УПК РФ)

При рассмотрении уголовного дела, представленного ему с обвинительным заключением, прокурор может принять одно из следующих решений: об утверждении обвинительного заключения и о направлении уголовного дела в суд; о возвращении уголовного дела следователю для производства дополнительного следствия, изменения объема обвинения либо квалификации действий обвиняемых или пересоставления обвинительного заключения и устранения выявленных недостатков со своими письменными указаниями; о направлении уголовного дела вышестоящему прокурору для утверждения обвинительного заключения, если оно подсудно вышестоящему суду.

В ч. 2 ст. 221 УПК РФ законодатель сохранил важное средство прокурорского реагирования, направленное на защиту прав обвиняемого: «Установив, что следователь нарушил требования части пятой статьи 109 настоящего Кодекса, а предельный срок содержания обвиняемого под стражей истек, прокурор отменяет данную меру пресечения».

Чтобы было понятно, о чем идет речь в этой статье, укажем, что в ч. 5 ст. 109 УПК РФ установлено, что материалы оконченного расследованием уголовного дела должны быть предъявлены обвиняемому, содержащемуся под стражей, и его защитнику не позднее, чем за 30 суток до окончания предельного срока содержания под стражей.

В п. 15 ч. 2 ст. 37 УПК РФ содержится очень важное положение, которое во многом определяет процессуальную самостоятельность следователя при решении ряда правовых вопросов по уголовному делу, которое он расследует.

В соответствии с этой нормой прокурор имеет право возвращать уголовное дело следователю со своими письменными указаниями о производстве дополнительного расследования, об изменении объема обвинения либо квалификации действий обвиняемых или для пересоставления обвинительного заключения и устранения выявленных недостатков. Эти положения рассматриваемой нормы полностью совпадают с нормой, указанной в п. 2 ч. 1 ст. 221 УПК РФ, рассмотренной нами выше.

Как же быть следователю в тех случаях, когда он не согласен с полученными от прокурора указаниями?

В п. 5 ч. 2 ст. 38 УПК РФ указывается, что следователь уполномочен обжаловать с согласия руководителя следственного органа в порядке, установленном ч. 4 ст. 221 УПК РФ, решения прокурора об отмене постановления следователя о возбуждении уголовного дела, о возвращении уголовного дела следователю для производства дополнительного следствия, изменения объема обвинения либо квалификации действий обвиняемых или пересоставления обвинительного заключения и устранения выявленных недостатков со своими письменными указаниями.

А далее в ч. 4 ст. 221 УПК РФ указывается, что постановление прокурора о возвращении уголовного дела следователю может быть обжаловано им в течение 72 часов с момента поступления к нему уголовного дела с согласия руководителя следственного органа вышестоящему прокурору, а при несогласии с его решением - Генеральному прокурору Российской Федерации с согласия Председателя Следственного комитета Российской Федерации либо руководителя следственного органа соответствующего федерального органа исполнительной власти.

Вышестоящий прокурор в течение 10 суток с момента поступления соответствующих материалов выносит одно из следующих решений: об отказе в удовлетворении ходатайства следователя или об отмене постановления нижестоящего прокурора. В этом случае вышестоящий прокурор утверждает обвинительное заключение и направляет уголовное дело в суд. В соответствии с ч. 5 ст. 221 УПК РФ обжалование следователем решения прокурора, указанного в п. 2 ч. 1 этой же статьи, приостанавливает исполнение решения прокурора.

В ч. 3 ст. 38 УПК РФ указывается, что в случае несогласия следователя с требованиями прокурора об устранении нарушений федерального законодательства, допущенных в ходе предварительного следствия, следователь обязан представить свои письменные возражения руководителю следственного органа, который информирует об этом прокурора.

Анализируя отношения следователя и прокурора в проблемных ситуациях, когда они взаимодействуют в связи с нарушениями закона, допущенными следователем, или в случае несогласия следователя с позицией прокурора по конкретному уголовному делу, обращает на себя внимание, что следователь имеет право обжаловать указания прокурора только с согласия руководителя следственного органа. На следственной практике такая норма приводит к тому, что следователь просто лишается права заявить прокурору о своей правовой позиции по уголовному делу. Вряд ли такой порядок целесообразно в УПК РФ сохранять дальше. 


\section{Право и политика - №8(152)•2012}

Если обратиться к опыту законодателя прошлых лет, то по УПК

РСФСР все дискуссионные вопросы о правильном и законном разрешении уголовного дела между следователем и прокурором решались более разумно.

Так, например, в соответствии с ч. 2 ст. 127 УПК РСФСР в случае несогласия следователя с указаниями прокурора о привлечении в качестве обвиняемого, о квалификации преступления и объеме обвинения, о направлении уголовного дела для предания обвиняемого суду или о прекращении уголовного дела следователь был вправе представить уголовное дело вышестоящему прокурору с письменным изложением своих возражений.

В этом случае прокурор или отменял указания нижес- тоящего прокурора, или поручал дальнейшее производство расследования по этому уголовному делу другому следователю. И такое решение законодателя было совершенно обосновано, так как нельзя понуждать следователя вопреки его убеждениям вести следствие по уголовному делу дальше, так как в дальнейшем это может обернуться серьезными судебными ошибками.

На наш взгляд, российскому законодателю ничего нового в правовых отношениях следователя и прокурора придумывать не надо, а следует просто восстановить в УПК РФ весьма обоснованную и разумную процессуальную норму об отношениях следователя с прокурором, которая содержалась в прошлом в ч. 2 ст. 127 УПК РСФСР.

Таковы кратко особенности правовых отношений следователя с прокурором в настоящее время по УПК РФ.

\section{Библиография}

1. Будченко В. Проверка поводов для возбуждения уголовного дела.//Законность. 2008. №11. С. 52-53.

2. Быков В. М. Новый закон о проверке следователем сообщения о преступлении. //Право и политика. 2011. №7. C.1115-1121.

3. Горленко В. А.Проблемы установления баланса полномочий следователя и прокурора в решении вопроса о возбуждении уголовногодела. //Следователь. 2011. №3. С. 16.

4. Григорьев В. Постановление прокурора - новый повод для возбуждения уголовногодела? //Законность. 2011. №8. C. 47.

5. Ережепалиев Д. Полномочия прокурора в стадии возбуждения уголовного дела. //Уголовное право. 2011. C.84.

6. Кругликов А.П. Проблемы процессуальных отношений прокурора со следователем и руководителем следственного органа. //Российская юстиция. 2011. №10. С. 29.

7. Соловьев А., Токарева М. Необходимо восстановить властно-распорядительные полномочия прокурора в досудебных стадиях российского уголовного судопроизводства. //Уголовное право. 2011. №4. С. 102.

\section{References (transliteration)}

1. Budchenko V. Proverka povodov dlya vozbuzhdeniya ugolovnogo dela.//Zakonnost’. 2008. №11. S. 52-53.

2. Bykov V. M. Novyy zakon o proverke sledovatelem soobshcheniya o prestuplenii. //Pravo i politika. 2011. №7. S.1115-1121.

3. Gorlenko V. A.Problemy ustanovleniya balansa polnomochiy sledovatelya i prokurora v reshenii voprosa o vozbuzhdenii ugolovnogodela. //Sledovatel'. 2011. №3. S. 16.

4. Grigor'ev V. Postanovlenie prokurora - novyy povod dlya vozbuzhdeniya ugolovnogodela? //Zakonnost’. 2011. №8. S. 47.

5. Erezhepaliev D. Polnomochiya prokurora v stadii vozbuzhdeniya ugolovnogo dela. //Ugolovnoe pravo. 2011. №4. S.84.

6. Kruglikov A.P. Problemy protsessual'nykh otnosheniy prokurora so sledovatelem i rukovoditelem sledstvennogo organa. //Rossiyskaya yustitsiya. 2011. №10. S. 29.

7. Solov'ev A.,Tokareva M. Neobkhodimo vosstanovit' vlastno-rasporyaditel'nye polnomochiya prokurora v dosudebnykh stadiyakh rossiyskogo ugolovnogo sudoproizvodstva. //Ugolovnoe pravo. 2011. №4. S. 102. 